\title{
Jean-Pons-Guillaume Viennet, Mémoires et Journal
} 1777-1867

\section{Franco Piva}

\section{Q OpenEdition}

1 Journals

\section{Edizione digitale}

URL: http://journals.openedition.org/studifrancesi/9584

DOI: 10.4000/studifrancesi.9584

ISSN: 2421-5856

\section{Editore}

Rosenberg \& Sellier

\section{Edizione cartacea}

Data di pubblicazione: 1 décembre 2007

Paginazione: 673-674

ISSN: 0039-2944

\section{Notizia bibliografica digitale}

Franco Piva, «Jean-Pons-Guillaume Viennet, Mémoires et Journal 1777-1867», Studi Francesi [Online], 153 (LI | III) | 2007, online dal 30 novembre 2015, consultato il 08 janvier 2021. URL: http:// journals.openedition.org/studifrancesi/9584 ; DOI: https://doi.org/10.4000/studifrancesi.9584

Questo documento è stato generato automaticamente il 8 janvier 2021.

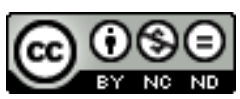

Studi Francesi è distribuita con Licenza Creative Commons Attribuzione - Non commerciale - Non opere derivate 4.0 Internazionale. 


\title{
Jean-Pons-Guillaume Viennet, Mémoires et Journal 1777-1867
}

\author{
Franco Piva
}

\section{NOTIZIA}

JEAN-PONS-GUILLAUME VIENNET, Mémoires et Journal 1777-1867, texte établi, présenté et annoté par Raymond TROUSSON, Paris, Honoré Champion, 2006, «Bibliothèque des correspondances, mémoires et journaux», pp. 1564.

1 Militare per tradizione familiare, e uomo politico al tempo della Restaurazione, troppo ruvido e indipendente tuttavia per fare carriera, Viennet cercò la gloria nelle lettere, per le quali dimostrò fin da giovane una passione tanto forte e tenace quanto poco fortunata. Figlio di quel xviii secolo che non rinnegò mai, fedele sino alla morte a quel «goût» che proprio Voltaire, meglio di altri, aveva definito e diffuso, Viennet cercò la gloria nel teatro: con poca fortuna, però, sia per l'insufficienza del suo genio, sia per una sorta di opposizione che il suo spirito caustico, assai più della cattiva volontà degli attori della Comédie-Française, contribuisce, se non a giustificare, almeno a spiegare. Molte delle pièces, tutte di stampo nettamente neoclassico, che compose nella sua lunga e ostinata carriera teatrale rimasero nel cassetto; mentre quelle poche che riuscirono a essere rappresentate non ebbero grande successo, quando, come nel caso di Sigismonde de Bourgogne, messa in scena dopo innumerevoli rinvii, nel 1825, non si risolsero in veri e propri «fiaschi». Fu più fortunato nella satira, che gli attirò però, come era inevitabile, più nemici che amici, e come autore di fables che interpretò con una notevole originalità e che gli procurarono, nella seconda parte della sua vita, una sorta di fama, aprendogli le porte dell'Académie française. Il successo vero lo conobbe con alcuni romanzi storici, composti alla maniera di Walter Scott, allora di gran moda in Francia, ma non ebbe il coraggio di proseguire su una strada che, evidentemente, contrastava troppo con la sua formazione classica. Sicché il maggiore titolo di merito di questo letterato somme toute modesto, sta in quel Journal che Viennet iniziò a comporre, quasi au jour le jour abbastanza presto, e in quei Mémoires che trasse dalle note del suo 
diario per la parte della sua vita che va fino al 1817, e che Raymond Trousson ha, molto opportunamente, deciso di proporre, dopo le edizioni molto parziali che degli uni e dell'altro erano apparse nella prima metà del secolo scorso, nella loro integralità e in un testo molto accurato, tratto con non poca pena dal manoscritto originale conservato nell'archivio degli eredi.

Viennet è stato un osservatore molto lucido e attento, tanto dal punto di vista politico che dal punto di vista letterario, del difficile periodo storico che ebbe a vivere. Di quel periodo egli propone una lettura certamente parziale e in qualche modo anche soggettiva, che non per questo è tuttavia meno puntuale e interessante. «Familier des derniers survivants de l'Ancien Régime et de l'Empire - osserva Trousson nella sua lunga «Introduction», nella quale ricostruisce da par suo la vita e la carriera dell'autore - Viennet recueille auprès d'eux souvenirs, anecdotes et portraits, il tient à jour son obituaire et prend soin de retracer la carrière et le portrait des disparus. Homme de lettres, il tient un registre exact de la littérature dramatique d'un demi-siècle, analysant les œuvres avec autant de minutie que de sévérité et passant des plus grands - Hugo, Vigny, Nodier, Dumas - aux minores les plus oubliés, de Locmaria à DrapArnaud, d'Arlincour à Casimir Bonjour. Habitué des coulisses, il sait par cœur comédiennes et comédiennes, les rivalités et les vanités, les intrigues et les ambitions, il excelle dans les portraits, de Talma à Rachel, de Charles $\mathrm{X}$ à Louis-Philippe, au récit des fêtes et des émeutes, toujours témoin qui se veut impartial. Même s'il lui arrive de surfaire un peu son rôle de Cassandre dont les prophéties ne sont jamais écoutées».

Di quel periodo storico e letterario che lo vide sfortunato, e pur tuttavia attivo protagonista, Viennet ci propone una lettura che potremmo definire da «vinto», anche se mai dichiarato, la quale fa, tuttavia, bene il paio con quelle che, dello stesso periodo, ci hanno fornito i cosiddetti «vincitori», cui siamo certamente più abituati, ma che sono altrettanto parziali e incomplete di quella che ci propone Viennet. I giudizi da lui espressi su alcuni dei principali protagonisti di quel movimentato periodo politico e soprattutto letterario, possono sorprenderci, trovarci magari in netto disaccordo come là dove, a proposito del More de Venise di Vigny, egli scrive che quando «la vogue en sera passée, il ne restera de ce Vigny qu'un sot et un fat dont la postérité se moquera» (p. 688), oppure là dove definisce il teatro di Hugo «un des scandales de notre siècle littéraire», opera come esso è di un «esprit malade» (p. 702) e, a proposito de Le Roi s'amuse, scrive che «la politique de M. Hugo est aussi abominable que sa littérature» (p. 841): essi meritano tuttavia di essere letti con attenzione, confrontati con quelli, altrettanto esaltati ed esagerati, che espressero quelli dell'altra parte. Non fosse che per capire meglio le tensioni e le contraddizioni di quei decenni così complessi e importanti, le ragioni di scontri che, a distanza di tempo, rischiano di apparirci fin troppo banali, le articolazioni di battaglie che troppo spesso siamo portati a vedere, teleologicamente, come vinte in partenza, o per la forza stessa delle cose. Come dimostra molto chiaramente la testimonianza di Viennet, non fu così che vissero e sentirono quei conflitti e quelle tensioni i contemporanei, e non fu così, forse, che le cose andarono realmente. La lettura di testimonianze come quella di Viennet è utile non solo per la straordinaria messe di notizie che ci offre, ma anche, se non soprattutto, per la prospettiva diversa attraverso la quale le propone e le presenta. Dobbiamo quindi essere grati a Raymond Trousson per averci proposto, dopo i Souvenirs d'un sexagénaire di Antoine-Vincent Arnault - altro importante e per certi versi fondamentale testimone di quel periodo (cf. «Studi francesi», n. 145, p. 172) - i Mémoires e il Journal di Viennet, 
che proprio ad Antoine-Vincent Arnault succedette nel ruolo di segretario di quell'Académie française che di quel mondo di cui essi furono tra gli ultimi, e sfortunati, protagonisti era diventata, come è noto, assieme al Théâtre-Français, l'estremo baluardo. 